\title{
Biological Pollution in Libraries: A Case Study of the King Abdulaziz Public Libray, Kingdom of Saudi Arabia
}

\author{
Najah Goblan Algoblan ${ }^{1}$, Nehal Fouad Ismael ${ }^{2}$, Samiah Hamad Al-Mijalli ${ }^{3}$ \\ ${ }^{1}$ Department of Library and Information, Princess Nourah Bint Abdulrahman University, Riyadh, Saudi Arabia \\ ${ }^{2}$ Department of Library and Information, Alexandria University, Alexandria, Egypt \\ ${ }^{3}$ Department of Science and Mathematics, Princess Nourah Bint Abdulrahman University, Riyadh, Saudi Arabia
}

Email address:

algoblann@hotmail.com (N. G. Algoblan), nehal_fouad@yahoo.com (N. F. Ismael), shalmejale@pnu.edu.sa (S. H. Al-Mijalli)

\section{To cite this article:}

Najah Goblan Algoblan, Nehal Fouad Ismael, Samiah Hamad Al-Mijalli. Biological Pollution in Libraries: A Case Study of the King Abdulaziz Public Libray, Kingdom of Saudi Arabia. American Journal of Information Science and Technology. Vol. 5, No. 2, 2021 , pp. 40-47. doi: 10.11648/j.ajist.20210502.14

Received: May 7, 2021; Accepted: May 26, 2021; Published: June 9, 2021

\begin{abstract}
Biological pollution is a main problem that threatens the environment because of its great risks that negatively affect human health. Such risk is more increased in closed spaces than open ones. Being closed and insufficiently ventilated environment, libraries are highly liable to biological pollution and they may become fertile environments for the causes of pollution. The present study aims at measuring how extent the biological pollution level is in the King Abdulaziz public library in the Kingdom of Saudi Arabia and how suitable and safe it is as a workplace to librarians and reading place for visitors. It also reveals the librarians' awareness and understanding of biological pollution and its risks. The study uses case study approach and the experimental method to achieve the objectives and answer the questions it raised. It concludes that King Abdelaziz Public library suffers from high air pollution and books may form the most concentrated colonies of bacteria. It finally recommends that environmental factors that help the growth and reproduction of microbes in the internal library environment must be under control, library pollution level must be measured periodically, laws and regulations that maintain a healthy environment for librarians should be enacted and regulated and must be Implemented an environmental management system that contributes effectively to eliminate pollution
\end{abstract}

Keywords: Biological Pollution Risks, Biological Pollution, King Abdulaziz Library, Librarian's Occupational Safety, Public Library

\section{Introduction}

Pollution is an environmental phenomenon that takes a large part of all governments' attention because of its negative impact on the health of individuals. Biological pollution is as old as the human being is on earth [1]. It results from visible and invisible living organisms, whether they are plant or animal [2].

Libraries are institutions that have an integral part of the environment, and they have special importance of intellectual and cultural heritage that should be secured. Therefore, libraries should be environmentally protected and preserved, because the environmental safety of libraries is fundamental to the safety of their users, and librarians.

\section{Background Literature}

Many studies dealt with library pollutants in different areas of the world, however, the intellectual contributions of biological pollution of libraries in Arab countries is still lacking. The following section presents intellectual production of related studies.

Dalal et al. traced the extent of fungal contamination of office materials in some libraries in Wardha city, India. The study classified as a type of biological pollution research and its results indicated that many fungi clearly spread in air or books. The study also confirmed that the fungi are primarily responsible for the paper and book damage in libraries, as well as affect significantly the health of librarians [3].

Hayleeyesus and Manaye measured the concentration of 
bacteria and fungi in the internal environment of the Jemaa University libraries, Ethiopia. The most important result was that indoor air in Jimma University libraries was heavily contaminated with bacteria and fungi and recommended which the study also concluded, was drawing attention to the necessity of controlling environmental factors that lead to the growth and reproduction of microbes in library internal environment to preserve the health of the users and librarians [4].

Huixing, et al. analyzed and evaluated comprehensively air quality standards in reading rooms at one of the university libraries in China. A questionnaire was also distributed to university students, tracking some diseases they were suffering, such as insomnia, depression, tinnitus, tired eyes, and dry skin. The results clearly showed that visitors' food and drinks were the cause beyond internal pollution. The low rate of humidity in the library led to dry skin and dry eyes [5].

Balocco et al. determined how the internal environment is suitable to preserve the archive heritage of the historical Palatina Library in Italy. The most important finding of the study was that microorganisms are responsible for causing damage to the paper materials in the archives [6].

Cincinelli et al. tracked air quality in libraries and archive buildings in Florence, Italy. They sought the characteristics of air quality in such places and found that there are some high-concentrated compounds that have an effect on book and paper oxidation and damage [7].

Huixing et al. The study aimed at finding out the level of indoor particles at the Shenyang University Library in China. And indicated that indoor pollution has become a real danger and suspended particles in the atmosphere in the indoor environment are one of the most essential factors that affect the health [8].

Jung et al. conducted swab samples from 42 children's books collected from four public libraries in Texas and California. All 42 samples were positive in terms of bacterial growth and the occurrence of bacteria grown in ampicillincontaining medium is much higher than the occurrence of bacteria grown in kanamycin-containing medium This study demonstrates the utility of proteomics in identifying environmental pathogenic bacteria for specific public health risk evaluations [9].

The present study is the same as previous studies in measuring the level of biological pollution with its different causes in libraries, however, its experimental field and application are different, as it will be applied to Arabic environment, which is different from other environments and the topic of biological pollution in its libraries is still lacking. Accordingly, the researchers hope that this study will contribute to filling the gap in research and enriching the Arabic library on this subject.

\section{Theoretical Framework}

\subsection{The Concept of Biological Pollution}

Biological pollution consists of various reproductive bodies such as viruses, bacteria, and parasites. Biological pollution occurs as a result of microorganisms polluting increase in the environmental medium (i.e., water, air, soil) and pathogens, such as bacteria, viruses, parasites, and algae. Specifically, biological pollution results in some pathogenic organisms that affect human health [10].

\subsection{Causes of Biological Pollution in Libraries}

There are many causes of biological pollution in libraries, including the following:

Rodents and insects

Factors of temperature and humidity.

Lack of good ventilation.

The cellulose material of paper pages, which is a source of food for some fungi [11].

Drinks and food that library workers fetched to library.

\subsection{Library Environmental Management System for Reducing Pollution}

The institutional adoption of environmental management systems, regardless of type or size, has become a basic requirement in this era because planning management system is usually involved in an institutional strategy that aimed at improving its environment. The application of the environmental management system effectively contributes to eliminating pollution [12]. US Agency for Environmental Conservation (EMS) defined an environmental management system as a set of processes and activities that enable the organization to reduce environmental influences and increase its operational efficiency [13].

In 1996, the International Standardization Organization (ISO) issued a series of international standards ISO 14000, which is a standard for service and industrial institutions to build environmental management systems through which they seek to make organization pay attention to environmental concerns. Such specifications essentially seek to handle environmental problems at the beginning and not at the end line. The international standards ISO 14000 series resulted in sub-specification ISO 14001, which is highly essential standard because it helps institutions formulate their environmental policy. The basis of building an environmental management system depends on the senior management to develop and adhere to a clear and documented environmental policy that has great roles in libraries as follows:

Increasing the employees' awareness of the necessity and importance of maintaining library environment.

Increasing the users' awareness of the importance of keeping library environment clean and tidy.

Reducing pollution in libraries.

Readiness to face any risks in libraries.

Showing staff responsibilities in implementing the environmental policy in library.

Determining the negative impacts resulting from human and technical activities in library.

In sum, it can be said that environmental management systems are a library managerial tool that helps address 
and handle environmental problems on one hand and limit or control risk in information institutions on the other.

\section{Methodology}

\subsection{Problem of the Study}

The internal environmental safety of libraries has not received sufficient attention in the Arab world. Biological pollution is one of the environmental problems facing some libraries because of being a closed and unventilated environment, making it a fertile environment for the indoor causes of pollution. Pollutant high concentration in a small, closed, and non-renewable ventilated space is much more dangerous than its concentration in an open, renewable, and ventilated space. Therefore, libraries are more liable to many various pollutants, including biological pollutants, which represent a danger that threatens the library environment. Biological pollution also poses a serious risk because it negatively affects the safety and health of both librarians and users alike.

King Abdulaziz Public Library is an essential public library in the Kingdom of Saudi Arabia, as it is open to all segments and classes of society, as well as it is a suitable environment for measuring the topic of biological pollution the present study has taken on. In this respect, the study seeks to answer the following questions.

1. What is the level of biological pollution in the King Abdulaziz Public Library?

2. How appropriate is the environment of the King Abdulaziz Library to work safely for the librarians and provide safe reading places for the users?

3. What are the dangers of biological pollution in the King Abdulaziz Library?

4. How aware are librarians at the King Abdulaziz Library of the concept and dangers of biological pollution?

5. What preventive measures and procedures are the King Abdulaziz Library taking to reduce biological pollution?

\subsection{Objectives of the Study}

Measuring the extent of biological pollution in the King Abdul Aziz Public Library.

Finding out how suitable the environment of the King Abdulaziz Library is for librarians to safely work and provide proper reading rooms for users.

Learning more about how extent librarians at the King Abdulaziz Library are aware of the concept and dangers of biological pollution.

Assessing biological pollution dangers in the King Abdulaziz Library.

Finding out the preventive measures are the King Abdulaziz Library taking to reduce biological pollution

\subsection{Importance of the Study}

The present study serves as an early warning to all library managers to avoid the effects of biological pollution. It also contributes in protecting library staff, ensuring their professional safety, and providing a safe reading environment for users through formulating preventive measures to reduce biological pollution in libraries. In doing so, it helps provide a healthy working environment and contribute to the management of risks in libraries.

\subsection{Approach and Tools of the Study}

The study used case study approach and the experimental method.

Case Study Approach

The Case Study helps explore and analyze the library internal environment. To achieve the study objectives and answer partially its questions, the researchers designed a questionnaire based on background literature. The questionnaire included three axes: the first dealt with the study community characteristics. The second was exploring biological pollution awareness as a concept and its risks. Finally, the third covered the preventive measures that reduce biological pollution. Three specialized professors in libraries and microbiology reviewed the questionnaire. Their feedback of a number of paragraphs were added in the last section accordingly.

The interview is the second tool that the study used to find out more factual details and explanations of the study sample. Personal interviews were conducted with the library director and the librarians.

Experimental Approach

The study used the experimental approach to answer the questions concerning pollution levels through the samples that were taken from the library for microscopic analysis.

Samples were obtained from shelves, books, tables, book pages, bookshelves, by sterile swab method and air sample by exposing the Agar media to the air within different places of library for 10 minutes. Isolates were identified according to standard methods. The growth media were Nutrient agar, Blood agar and Potato dextrose agar. Plates were placed in an incubator at $37^{\circ} \mathrm{C}$ for 24 hours

Isolation. Identification of Bacteria from different places of Library bacterial

Isoalates were identified by the use of VITEK 2. This automated system uses a variety of identification cards and antibiotic susceptibility cards that contain wells of substrates and antibiotics used to identify each species of bacterium

Population of the Study

The study population is the King Abdulaziz Public Library, which is the largest public library in Riyadh. The library includes 85 employees of specialized staff, who are distributed over the library departments. It is also divided into two sections; one is for men and the other for women that includes a section for children. Accordingly, the questionnaire was distributed to all library employees with 76 librarians and participants in total. The participation rate was $89.4 \%$ of the study sample. "Table 1" shows the sample 
characteristics.

Table 1. The sample characteristics.

\begin{tabular}{|c|c|c|c|c|c|c|}
\hline \multirow{2}{*}{$\begin{array}{l}\text { Employees of King Abdulaziz } \\
\text { Library }\end{array}$} & \multicolumn{2}{|l|}{ Gender } & \multirow{2}{*}{ Total } & \multicolumn{2}{|l|}{ Workplace } & \multirow{2}{*}{ Total } \\
\hline & Male & Female & & Men's Section & Women's Section & \\
\hline Frequency & 39 & 37 & 76 & 42 & 34 & 76 \\
\hline Percentage & $51.3 \%$ & $48.7 \%$ & $100 \%$ & $55.3 \%$ & $44.7 \%$ & 100 \\
\hline \multicolumn{7}{|l|}{ Employee's Age } \\
\hline Employee's Age & Older than 40 & $35-40$ & $30-35$ & $25-30$ & $20-25$ & Total \\
\hline Frequency & 40 & 11 & 11 & 6 & 2 & 76 \\
\hline Percentage & 60.5 & 14.5 & 14.5 & 7.9 & 2.6 & 100 \\
\hline
\end{tabular}

\section{Practical Framework}

The following section answers the study.

\subsection{The Level of Biological Pollution in the King Abdul Aziz Public Library}

The indoor air in library was highly contaminated according to WHO guidelines and European Commission classification. All the air inside the Library was contaminated with fungi and bacteria. Total 85 bacterial isolates were collected from the bookshelves, tables, books, and air. Table 6 show Bacterial concentration in library locations [14, 15].

Table 2. Bacterial concentration in library locations.

\begin{tabular}{ll}
\hline $\mathbf{C F U} / \mathbf{m}^{\mathbf{3}}$ & Location \\
\hline 3200 & Book shelf \\
5700 & Library books \\
3600 & Library table \\
4200 & Library AIR \\
\hline
\end{tabular}

Table 2 shows that books are the most concentrated colonies of bacteria. This is because book paper is an organic material consisting of cellulose; moreover, the proteins of book covers provide an ideal medium for the growth of many microorganisms [16] particularly most shelves King Abdul Aziz Public Library are closed, which result in decreasing the rate of air exchange and poor ventilation. It also shows that there is a high bacterial concentration in the air, according to The Commission of the European Communities (CEC). The CEC defines the following level of bacteriological air contamination: 0 undetectable, $1-499 \mathrm{CFU} / \mathrm{m}^{3}$ low, 500-999 $\mathrm{CFU} / \mathrm{m}^{3}$ medium, $>1,000 \mathrm{CFU} / \mathrm{m}^{3}$ high, and $2,000 \mathrm{CFU} / \mathrm{m}^{3}$ very high. A value of $10,000 \mathrm{CFU} / \mathrm{m} 3$ of nondescript airborne microbes could therefore be considered a hazardous level for indoor environment.

\subsection{How Appropriate the Environment of the King Abdulaziz Library Is for Librarians to Safely Work and Provide Proper Reading Rooms for Users}

The librarians who work with dusty books are in health danger. The most isolates like Acinetobacter haemolyticus, $\mathrm{S}$. pneumoniae and staphylococcus aureus are considered as potentially pathogenic candidates and are often associated with clinical manifestations like urinary tract infections, pneumonia, respiratory illnesses, rhinitis, asthma and conjunctivitis and skin problems.

The results of the present study are broadly consistent with Jung et al. ${ }^{9}$ that showed the most common bacteria in the library were S. pneumonia and staphylococcus aureus. S. pneumonia is particularly dangerous for young children, older adults, and persons with underlying comorbidities.

"Table 3" and "Table 4" show the organisms found in women and men library sections, and may result in diseases of real dangers to workers and visitors alike.

Table 3. Organisms Spotted in Women's Library Section.

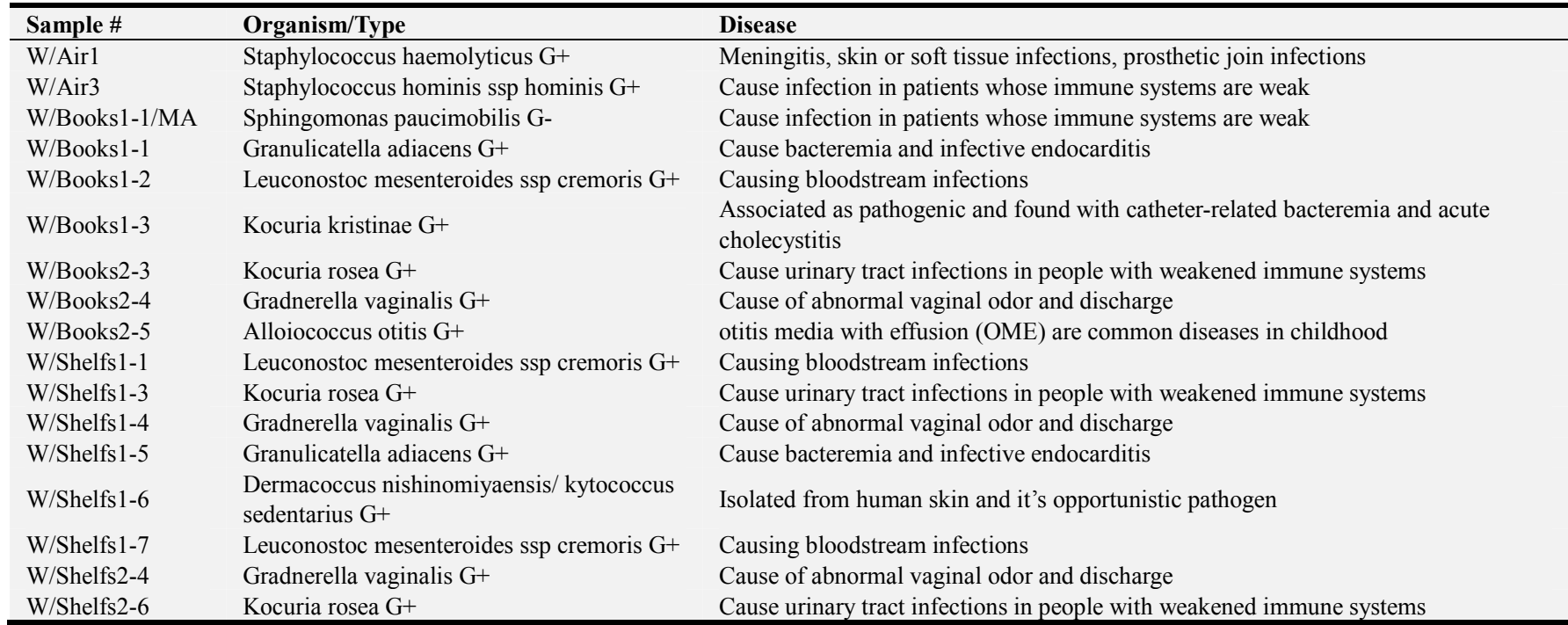




\begin{tabular}{lll}
\hline Sample \# & Organism/Type & Disease \\
\hline W/Tables1-1 & Kocuria kristinae G+ & $\begin{array}{l}\text { Associated as pathogenic and found with catheter-related bacteremia and acute } \\
\text { cholecystitis }\end{array}$ \\
W/Tables2-1 & $\begin{array}{l}\text { Staphylococcus hominis ssp hominis G+ } \\
\text { Cause infection in patients whose immune systems are weak } \\
\text { W/Tables2-3 }\end{array}$ & $\begin{array}{l}\text { Cause bacteremia and infective endocarditis } \\
\text { Associated as pathogenic and found with catheter-related bacteremia and acute } \\
\text { W/Tables2-4 }\end{array}$ \\
\hline
\end{tabular}

Table 4. Organisms Spotted in Men's Library Section.

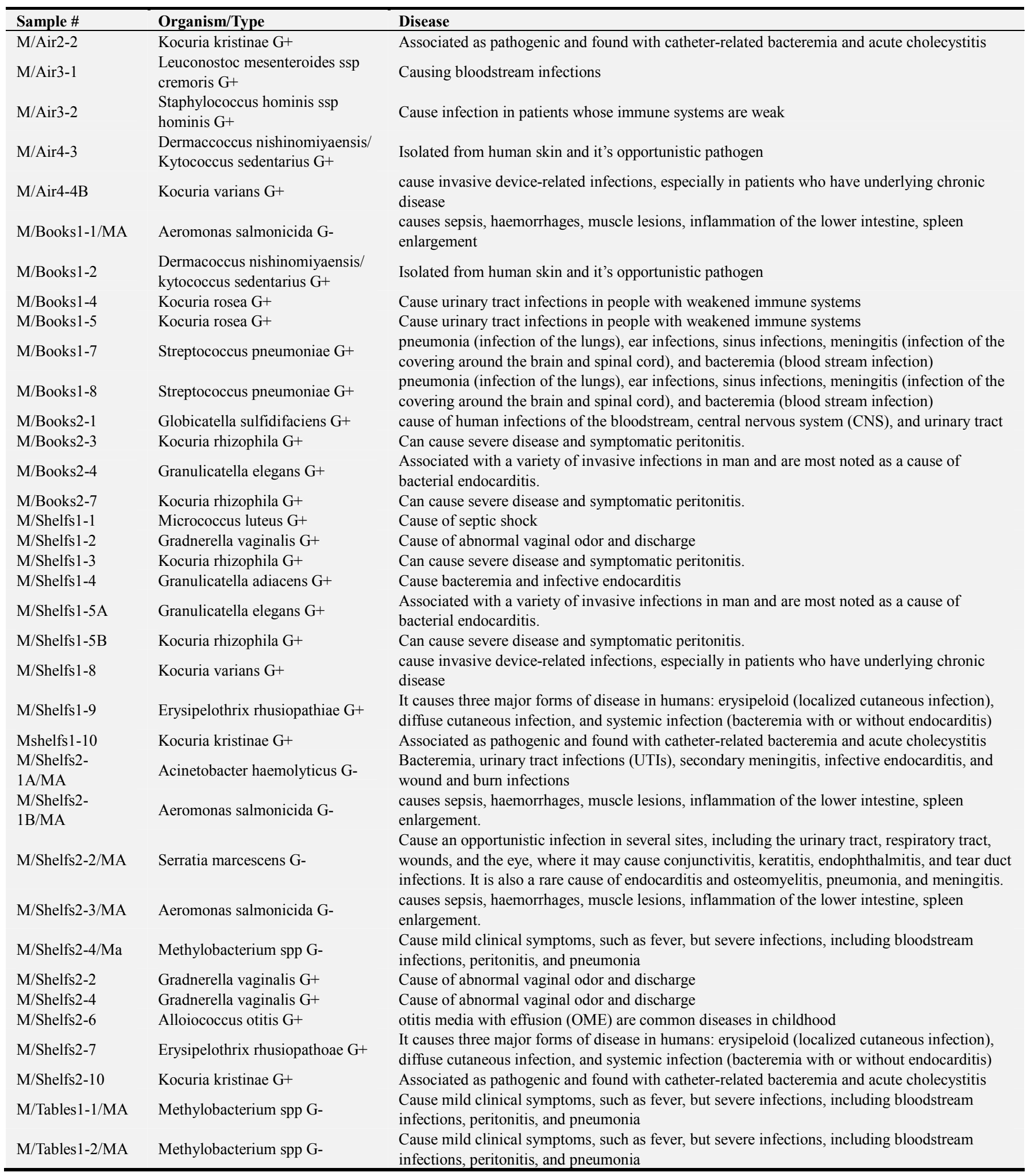




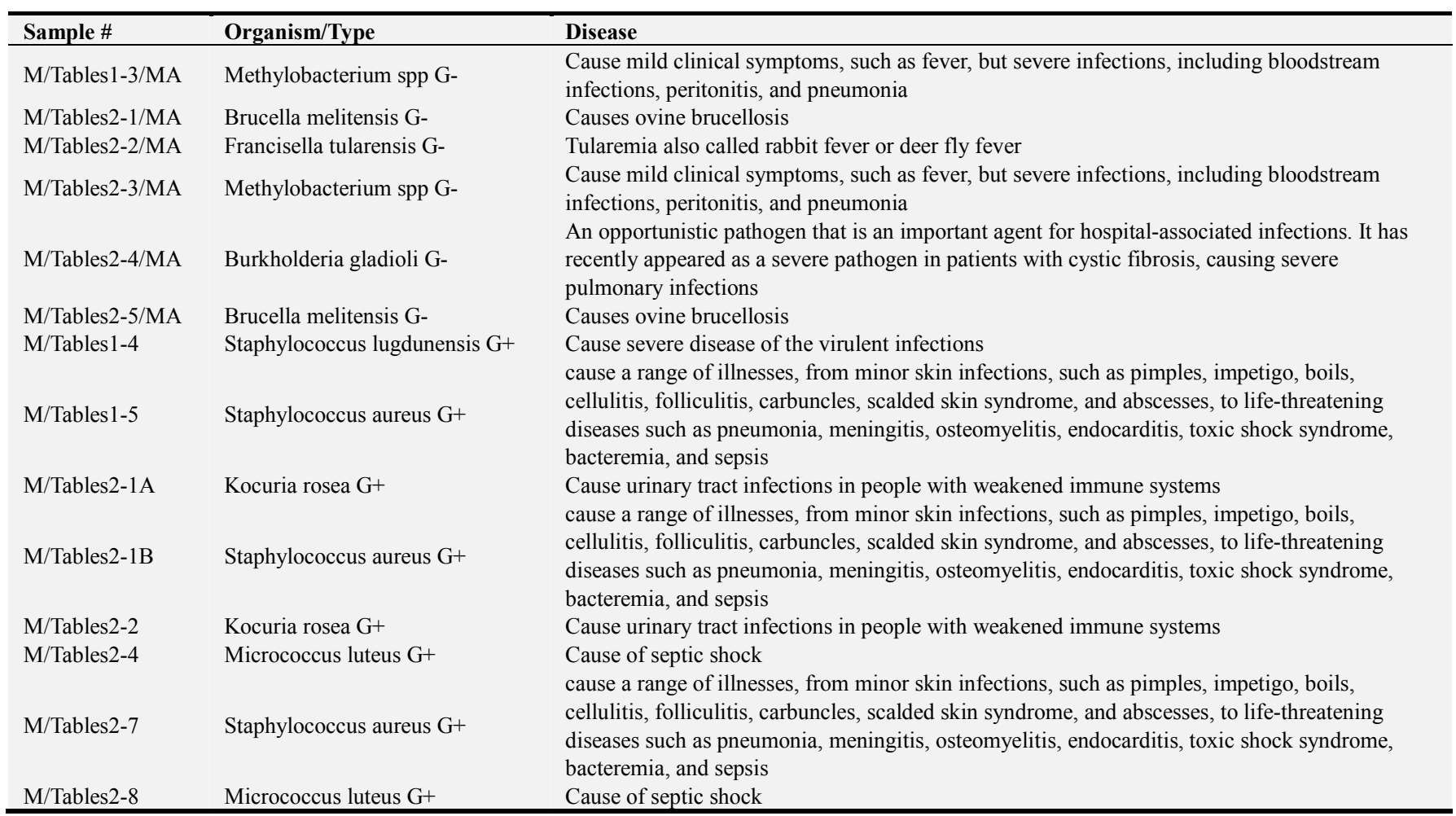

Tables 3 and 4 show that microbial contamination inside the library can pose a major health risk to library workers and visitors, so there is a need to improve indoor air quality in Library to provide better healthy breathing environment for users.

\subsection{Employees' Knowledge of Biological Pollution Risks}

Table 5. Employees' awareness of the concept of biological pollution.

\begin{tabular}{|c|c|c|}
\hline The concept of biological pollution & Frequency & Percentage \\
\hline Environmental corruption that individuals live and there is an apparent and latent risk to their health and safety. & 11 & 14.5 \\
\hline Humans and their activity change of the surrounding environment that leads to living organism's imbalance. & 18 & 23.7 \\
\hline Visible or invisible organisms that exist in the environment and lead to human disease. & 47 & 61.8 \\
\hline Total & 76 & 100 \\
\hline
\end{tabular}

Table 5 refers that a large percentage of the study participants are aware of the biological pollution concept; $61.8 \%$ of respondents know the correct concept, whereas
$38.2 \%$ of them do not know and unaware of the concept, which indicates that they need to learn more about the concept.

Table 6. Opinion of librarians about the library environment safety.

\begin{tabular}{lll}
\hline Library safety against biological pollution & Frequency & Percentage \\
\hline Yes & 28 & 36.8 \\
No. & 48 & 63.2 \\
Total & 76 & 100 \\
\hline
\end{tabular}

Table 7. Participants' distribution according to the diseases they suffer.

\begin{tabular}{lll}
\hline Diseases & Frequency & Percentage \\
\hline skin diseases & 32 & 42.1 \\
respiratory diseases & 25 & 32.8 \\
Intestinal diseases & 6 & 7.8 \\
Eye diseases & 18 & 23.6 \\
Cancerous diseases & 0 & 0 \\
Venereal diseases & 0 & 0 \\
Heart Disease & 0 & 0 \\
\hline
\end{tabular}

Table 6 indicates that $63.2 \%$ of librarians reported that the library environment is not safe. This large percentage of the participants, who are convinced of library unsafe environment, refers to the majority awareness. Conversely, $36.8 \%$ of members said that the library is not a contaminated environment of biological pollution.

Table 7 shows that the diseases that afflict employees can be classified proportionally as follows:

1. skin diseases.

2. Respiratory diseases.

3. Eye diseases

4. Intestinal diseases.

"Table 3" and "Table 4" revealed that the organisms that were spotted in the library may cause various diseases, such as respiratory diseases, including pulmonary infection, 
sinusitis, asthma, and eye diseases, including conjunctivitis, keratitis, and skin diseases, including pimples, impetigo, boils, cellulitis, folliculitis, carbuncles, scalded skin syndrome, and abscess. Intestinal diseases, including inflammation of the lower intestine and cholecystitis. It is consistent with the classification of diseases that the study sample concluded.

\subsection{Preventive Measures and Procedures to Reduce Biological Pollution In The King Abdulaziz Library}

Table 8. Lists the preventive measures to reduce biological pollution in the King Abdulaziz Library.

\begin{tabular}{|c|c|c|c|}
\hline Serial & Action & Frequency & Percentage \\
\hline 1 & Dealing with a high quality cleaning company. & 61 & 80.3 \\
\hline 2 & Contracting with companies for periodic library sterilization. & 51 & 67.1 \\
\hline 3 & Provide personal protection tools for employees and visitors. & 50 & 65.8 \\
\hline 4 & Provide sterilization devices. & 44 & 57.9 \\
\hline 5 & Assigning a committee to follow up Safety and health in the library environment & 31 & 40.8 \\
\hline 6 & Enacting laws or regulations in the library to maintain a healthy environment for librarians & 5 & 6.5 \\
\hline 7 & Provide guidance and instructions on precautionary measures to prevent the dangers of biological pollution & 6 & 7.8 \\
\hline
\end{tabular}

Table 8 shows the preventive measures and procedures that King Abdulaziz Public Library have taken to reduce biological pollution from the participants' viewpoint. It also shows that dealing with a high-quality cleaning company comes on the top with $80.3 \%$, followed by contracting with sterilization companies with $67.1 \%$. Although the procedures are at a high standard level of protection, the applied section in "Table 3" and "Table 4 show up large bacterial pollution in the library, which indicates that it is necessary to review the sterilization mechanisms, as well as to measure the percentage of pollution after sterilization process.

Providing personal protective equipment to employees and visitors came in third and fourth place, with $65.8 \%$ as well as providing sterilization devices with $57.9 \%$. Personal interviews revealed that there is one sterilization device which is used to sterilize new manuscripts and books only upon receipt.

The least preventive measures of reducing biological pollution are enacting laws or regulations in the library to maintain a healthy environment for librarians with $6.5 \%$.

\section{Conclusions}

The current study concluded that there is a bad need to improve the indoor air quality in the King Abdulaziz Library to provide a better and healthy breathing environment inside the library. In addition, the microbial pollution inside the library can form a health risk to librarians and visitors. The study resulted in a number of diseases that microbial pollution can cause, including skin infections, pneumonia, ear infections, conjunctivitis and keratitis, sinus infections, urinary tract infections, cholecystitis, lower intestine inflammation, membrane inflammation around the brain and spinal cord, bloodstream infections, and Bacteremia. It is consistent with the diseases they librarians suffer in King Abdulaziz Library.

The study revealed that librarians are aware of the concept of biological pollution.

The study also found out that the most preventive measure that King Abdel Aziz library can take to reduce and avoid biological pollution is contract with a high-quality cleaning company and contracting for periodically sterilizing the library and providing personal protection tools for employees and visitors. However, the percentage of preventive measures for enacting laws or regulations in the library and for preserving a healthy environment for the librarian is at very low level.

\section{Recommendations}

Surrounding air quality is an important criterion to provide a healthy and safe environment. Therefore, harmful air microbes must be avoided or at least be kept at too lower level to cause disease.

Environmental factors that help the growth and reproduction of microbes in the internal library environment must be under control

Measuring library pollution level periodically

Periodic checks for employees in library

Enacting laws and regulations that maintain a healthy environment for librarians.

Implementing an environmental management system that contributes effectively to eliminate pollution

Fixing guidelines and instructions in libraries on precautionary measures to prevent biological pollution dangers and risks

Providing natural plants, it absorbs air pollutants.

Using an anti-bacterial paint.

Setting courses for librarians on occupational safety.

Finally, it becomes factual to say that environmental awareness has been an essential issue in recent times, particularly after spreading COVID-19 over the world. As such, environmental awareness aims at establishing ethics and positive health conduct among librarians and users alike, because keeping and protecting library environment from pollution needs awareness.

\section{References}

[1] Nasrallah S. Legal protection of the environment from pollution in international humanitarian law. MA Thesis, Université Badji Mokhtar, Algeria, 2011. 
[2] Saeed F. Environmental preservation and health awareness. Cairo: Taibah Foundation for Publishing and Distribution, 2010, p. 34

[3] Dalal L, Bhowal $M$ and Kalbende $S$. Incidence of deteriorating fungi in the air inside the college libraries of Wardha city. Archives of Applied Science Research 2011; 5: 479-485.

[4] Hayleeyesus SF and Manaye AM. Microbiological Quality of Indoor Air in University Libraries. Asian Pacific Journal of Tropical Biomedicine 2014; 4: 312-317.

[5] Huixing Li, Chengcheng T, Yibo Z, et al. Measurement and evaluation to the library reading room pollutants. Procedia Engineering 2015; 121: 1836-1843.

[6] Balocco C, Petrone G, Maggi O, et al. Indoor microclimatic study for Cultural Heritage protection and preventive conservation in the Palatina Library. Journal of Cultural Heritage 2016; 22: 956-967.

[7] Cincinelli A, Martellini T, Amore A, et al. Measurement of volatile organic compounds (VOCs) in libraries and archives in Florence (Italy). Science of the Total Environment 2016; 572: 333-339.

[8] HuiXing L, YuHua Q and GuoHui F. The analysis of PM2.5 Outdoor Fine Particulate Matter Impact on Air Quality in the University Libraries Reading Room in Winter of North China in Procedia Engineering 2017; 205: 3346-3352.

[9] Jung RH, Kim M, Bhatt B, et al. Identification of Pathogenic
Bacteria from Public Libraries via Proteomics Analysis. International Journal of Environmental Research and Public Health 2019; 16: 912.

[10] Jasim A. Readings in Biological and Genetic Contamination Beatona Journal 2009; 120: 48-49.

[11] Kayarkar A and Bhajbhuje M. Biodiversity of Aeromycoflora from Indoor Environment of Library. International Journal of Life Sciences 2014; 2: 21-24.

[12] Abdul Karim M. The Role of the Environmental Management System in Achieving the Competitive Advantage of an Economic Enterprise: A Case Study on the Cement Factory SCAEK. MA thesis, University Ferhat Abbas Setif, Algeria, 2012.

[13] Othman H. The role of Environmental Management in Improving Environment performance of Economy Institution in: International Scientific Conference on Sustainable Development and Efficiency of Using Available Resources, $7-$ 8April, p 523. Algeria: University of Setif.

[14] World Health Organization. WHO guidelines for indoor air quality: dampness and mould. Denmark: WHO, 2009.

[15] Commission of the European Communities. Indoor air quality and its impact on man. Report for Biological particles in indoor environments. Report no. 12, 1993. Luxembourg: CEC.

[16] Hempel M, Rakhra V, Rothwell A, et al. Bacterial and fungal contamination in the library setting: a growing concern? Environmental Health Review 2014; 57: 9-15. 